\title{
MAKANAN HANTARAN PADA UPACARA PERKAWINAN DI DESA SUNGAI ABU KECAMATAN HILIRAN GUMANTI KABUPATEN SOLOK PROVINSI SUMATERA BARAT
}

\author{
Sofnitati ${ }^{1}$ \\ ${ }^{1)}$ Staf Pengajar Jurusan Kesejahteraan Keluarga Fakultas Pariwisata dan Perhotelan \\ Universitas Negeri Padang \\ Email: sofnitatipkkunp@gmail.com
}

\begin{abstract}
Abstrak. This study aims to reveal: 1) a series of Hantaran custom ceremonies, (2) type of Hantaran custom food, (3) equipment used to bring Hantaran custom food, (4) the meaning of food at the Hantaran ceremony. The type of this research is qualitative research, the object of research is Hantaran custom food that is brought on the Hantaran event in the Sungai Abu Village. The results showed that the Hantaran event in the Sungai Abu Village held the second day at the wedding ceremony, the series of Hantaran events in the Sungai Abu Village has two stages of preparation before the event and the series of Hantaran custom ceremonies, the type of food served at the Hantaran ceremony as many as 23 types and their meaning as a symbol of niniak mamak and interests for both families.
\end{abstract}

\section{Keyword: Hantaran Food, Wedding Ceremony.}

\section{PENDAHULUAN}

$\begin{array}{cccc}\text { Hantaran merupakan acara } & \text { dimana keluarga anak daro pergi }\end{array}$ mengantarkan makanan kerumah marapulai dengan cara balarak dan makanannya dibawa dengan cara di jujung di atas kepala. Menurut Paramus (2012: 37) "Hantaran pernikahan merupakan salah satu ciri khas perkawinan di Indonesia yang memiliki perbedaan sesuai dengan adat istiadat masing-masing daerah, baik dari cara pelaksanaan maupun barang-barang atau makanan yang dipersiapkan untuk dibawa dan diserahkan, yang paling penting yaitu makanan tradisional yang menjadi ciri khas dari masing-masing daerah". Acara hantaran ini pada kenyataannya masih dilestarikan akan tetapi dalam pengolahnnya yang banyak berperan hanyalah ibu-ibu usia 60 tahunan, sementara ibu-ibu muda dan anak muda hanya membantu-bantu bagian penataan dan pembungkusan serta masih belum adanya literature dan dokumentasi mengenai makanan hantaran. Perlu adanya literature (buku sumber), dokumentasi mengenai adat diDesa Sungai Abu Kecamatan Hiliran Gumanti, khususnya makanan adat hantaran dan peralatan yang digunakan untuk membawa makanan adat pada pelaksanaan acara hantaran.Hal ini untuk menjaga kelestarian adat dan 
ketentuan-ketentuan sekaligus bisa dimanfaatkan oleh masyarakat pada umumnya dan generasi penerus pada khususnya. Diharapkan masyarakat Desa Sungai Abu tidak mengalami krisis pengetahuan tentang adat dan sebagai upaya untuk memelihara serta melestarikan nilai-nilai budaya tradisional sebagai inti jati diri masyarakat Desa Sungai Abu Kecamatan Hiliran Gumanti Kabupaten Solok.

Penelitian ini bertujuan untuk mengungkapkan: rangkaian pelaksanaan upacara adat hantaran, jenis makanan adat yang dibawa pada saat pelaksanaan upacara adat, peralatan yang digunakan untuk membawa makanan pada upacara adat dan makna makanan adat yang dibawa pada pelaksanaan upacara adat hantaran di desa Sungai Abu Kecamatan Hiliran Gumanti Kabupaten Solok.

\section{METODE PENELITIAN}

Jenis penelitian ini adalah kualitatif dengan menggunakan metode deskriptif, yaitu penelitian yang mencoba menggambarkan, menuturkan dan menafsirkan suatu fenomena yang terjadi pada masa sekarang.

Lokasi penelitian dilakukan di Desa Sungai Abu Kecamatan Hiliran Gumanti Kabupaten Solok, Jorong Balai Garabak di rumah Bapak Syahril dan Ibu Olin disamping SD 03 Rantau Kimpalan serta penelitian ini dijadwalkan pada tanggal 19 Mei - 19 Juni 2014.

Pengumpulan data dalam penelitian ini menggunakan teknik pemilihan Snow-Ball Sampling yaitu teknik penentuan sampel yang mulamula jumlahnya kecil, kemudian membesar. Dalam penelitian kualitatif teknik pengumpulan data yang utama adalah observasi (pengamatan), wawancara dan dokumentasi.

Teknik analisis data yang digunakan dalam penelitian ini adalah analisis deskriptif kualitatif, teknik analisis data dilakukan melalui tiga proses tahapan yaitu teknik analisis data dilakukan saat sebelum memasuki lapangan, selama dilapangan dan setelah dilapangan.

\section{HASIL DAN PEMBAHASAN}

\section{Rangkaian Upacara Adat Hantaran di desa Sungai Abu Kecamatan Hiliran Gumanti}

Rangkaian upacara hantaran memiliki dua tahapan yaitu persiapan sebelum acara dan rangkaian upacara adat hantaran. Persiapan sebelum upacara hantaran yaitu: a) mengolah makanan adat, b) penyusunan makanan adat, c) pembungkusan makanan adat, sedangkan rangkaian adat hantaran yaitu: a) Balarak, b) Penyerahan Dulang c) Duduk Basamo, d) Manyiriah dan e) Pulang ka Rumah.

Dari hasil penelitian rangkaian acara hantaran ini untuk memperlihatkan keluarga yang baru membina rumah tangga kepada seluruh warga nagari serta bertujuan untuk dapat memperkenalkan kedua belah pihak keluarga dan menjalin tali silaturahmi antar kedua belah pihak keluarga. 
2. Makanan Adat pada Upacara Hantaran di desa Sungai Abu Kecamatan Hiliran Gumanti Kabupaten Solok

Berdasarkan hasil penelitian, makanan untuk upacara Hantaran dapat dibedakan berdasarkan jenis dan jumlahnya, dimana jenis dan jumlah makanan adat pada upacara Hantaran di desa Sungai Abu yaitu Nasi lamak kuniang sebanyak 1 dulang besar empat tingkat, Singgang ayam 1 ekor, goreng ikan utuh 2 ekor, randang daging potongan besar 4 potong dijadikan 2 piring, telor mata sapi 3 buah, telor balipek 3 piring, pergedel kentang 4 piring, goreng kentang hias 4 piring, bunga kol 1 piring, agar-agar 2 buah, kue bolu 2 buah, kue hias 1 buah, telor dadar 2 bowl, rangdang bada 1 bowl, randang karambia cukia 1 bowl, dan manisan 1 bowl. Menurut Rony (2001:45) "Makanan adat yang dibawa untuk acara hantaran yaitu: pangek ikan 2 ekor dalam 1 talam, pangek ikan gurami satu ekor dalam 1 talam, singgang ayam satu ekor utuh, gulai kambing campur rebung/nangka muda, nasi lamak 1 talam, wajik 1 talam, nasi kunyik 2 talam (satu talam wajik badatak/keras), paniaram 1 talam yang disusun sedemikian rupa".

Berdasarkan hasil penelitian dan kutipan di atas bahwa semua makanan adat berbeda jenis dan jumlahnya disetiap daerah, makanan adat ini wajib dibawa dengan jumlah yang telah ditetapkan dan tidak boleh tinggal ataupun berlebih karena sudah menjadi ketentuan adat dan kesepakatan bersama.

3. Alat yang digunakan untuk membawa makanan adat pada upacara hantaran di Desa Sungai Abu Kecamatan Hiliran Gumanti Kabupaten Solok

Berdasarkan hasil penelitian, bahwa alat-alat khusus yang digunakan untuk membawa makanan adat pada upacara hantaran di desa Sungai Abu adalah dulang bulat besar yang terbuat dari kuningan, dulang berkaki, baki, piring kecil, piring ceper bulat besar, bowl keramik, tudung saji/tenong, kain bungkuihan, dan dalamak. Hal ini sesuai dengan adat Minangkabau, bahwa untuk membawa makanan adat menurut Pudja (1989:70) “Alat yang digunakan untuk membawa makanan adat terdiri dari dulang, dalamak, baki/talam, piring samba, piring ceper, cambuang, dan tudung saji”.

Berdasarkan hasil penelitian dan kutipan di atas, alat-alat yang digunakan untuk membawa makanan pada upacara adat umumnya menggunakan dulang, piring samba, piring ceper, cambuang, tudung saji dan dalamak.

4. Makna yang terkandung dalam Upacara Adat Hantaran di desa Sungai Abu Kecamatan Hiliran Gumanti Kabupaten Solok

Berdasarkan hasil penelitian, bahwa makna dari makanan adat Hantaran yaitu: Nasi Lamak 
Kuniang memiliki makna bahwa anak daro melepeskan masa lajangnya menuju kehidupan berumah tangga yang ditandai dengan warna kuning, artinya anak daro telah diwarnai dan tidak putih lagi. Selain itu, nasi lamak kuning ini memiliki arti ikatan keluarga yang satu dengan yang lainnya.

Congkoang ayam memiliki makna bahwa anak daro telah diserahkan seutuhnya kepada pasangan hidupnya, nasi sapareh artinya keluarga anak daro saling berbagi nasi dengan keluarga marapulai, randang daging melambangkan niniak mamak yang dituakan dalam adat nagari, randang bada melambangkan tuangku dalam adat nagari, randang karambia cukia artinya hiasan dari bundo kanduang, sambal telor dan sambal lainnya yang kecil-kecil artinya hiasan dalam nagari dan sebagai pelengkap yang harus ada dalam upacara perkawinan.

Manisan artinya sebagai teman untuk makan nasi lamak kuning dan harapan supaya keluarga yang baru dibina bisa berbuah manis dalam menjalin hidup berumah tangga, pinyaram berbentuk pipih nan buliah dilayangkan, artinya kelak kepala keluarga dapat memimpin dan bijaksana didalam keluarganya, godok putih memiliki makna bahwa dalam membina rumah tangga kelak kepala keluarga bisa menjadi benteng didalam rumah tangganya, kue bolu memiliki makna bahwa masyarakat Minangkabau menjalani kehidupan dengan ajaran agama dan adat istiadat, dan kue hias memiliki makna bahwa masyarakat Minangkabau menjalani kehidupan dengan pedoman agama dan adat istiadat.

\section{SIMPULAN DAN SARAN}

\section{Simpulan}

Berdasarkan hasil penelitian yang diperoleh dari observasi, wawancara, dokumentasi maka dapat diambil kesimpulan sebagai berikut: Upacara Hantaran di Desa Sungai Abu dilaksanakan hari kedua pesta perkawinan (baralek). Rangkaian acara hantaran ini memiliki dua tahapan yaitu persiapan sebelum upacara hantaran dan rangkaian upacara adat hantaran. Makanan adat pada upacara Hantaran di Desa Sungai Abu Kecamtan Hiliran Gumanti Kabupaten Solok. Jumlah makanan adat yang dibawa saat upacarah antaran di Desa Sungai Abu 23 jenis. Alat yang digunakan untuk membawa makanan dalam pelaksanaan acara adat hantaran sesuai dengan jenis makanannyayaitu nasi jujuang/nasi lamak kunyit dengan dulang tipis, nasi sapareh dengan dulang berkaki, gulai dengan rantang, kue dan agar diletakkan diatas baki, asam padeh dalam bowl segi, randang karambia cukia dan manisan dengan bowl, Untuk sambal-sambal yang lainnya menggunakan piring kecil/besar lalu disusun di atas dulang yang telah dialas dan godok serta kembang 
loyang juga diletakkan di atas piring kecil kemudian di susun diatas dulang. Makna yang terkandung dari makanan adat yang dibawa saat acara hantaran secara filosofis menggambarkan tentang keberadaan dari pemimpin adat di Minangkabau yaitu nasi lamak sebagai lambang dari malin, nasi kunyit melambangkan dubalang, pinyaram melambangkan urang gadang dalam nagari, Kembang Loyang merupakan pelengkap hidangan dan lambing dari masyarakat banyak yang menjadi sandi dalam nagari dalam melakukan pekerjaan, Kue hias dan kue bolu memiliki makna bahwa kedua mempelai menjalani kehidupan dengan pedoman agama dan adat istiadat.

\section{Saran}

Berdasarkan temuan, maka disarankan Bagi generasi muda untuk dapat mencintai sekaligus ikut turut berpartisipasi melestarikan adat budaya daerah yang dimiliki, sebaiknya diadakan penyuluhan tentang makanan adat oleh niniak mamak dan bundo kanduang Desa Sungai Abu, kepada masyarakat yang tidak mengerti dan mengetahui adat Desa Sungai Abu baik untuk ibu-ibu maupun generasi muda, masyarakat khususnya di Desa Sungai Abu Kecamatan Hiliran Gumanti untuk memberikan dorongan dan motivasi dalam mempertahankan budaya daerah, agar tidak hilang seiiring perkembangan zaman dan tetap terjaga kelestariannya guna

menambah aset budaya.

\section{Daftar Pustaka}

Armaini. 2004. Budaya Alam Minangkabau. Jakarta: PT Bumi Aksara.

Azami. 1994. Budaya Alam Minangkabau. Padang: Angkasa Raya.

Media. 2000. Kamus Lengkap Bahasa Indonesia. Media Centre.

Pudja, Arinton. 1989. Dapur dan Alatalat Tradisional Daerah Sumtera Barat. Jakarta: Departemen Pendidikan Dan Kebudayaan.

Roni, Aswil. 2001. Aneka Ragam Makanan Tradisional Minang

Kabau. Padang: Departemen Pendidikan Nasional Direktorat Jendral Kebudayaan Museum Negeri Propinsi Sumatra Barat. Adityawarman.

Sugiyono. 2005. Memahami Penelitian Kualitatif.

Bandung: CV. Alfabeta.

Sugiyono. 2010. Metode Penelitian

Kualitatif

Bandung: CV. Alfabeta.

Suryabrata, Sumadi. 2000. Metodologi

Penelitian. Jakarta: Raja Grafindo Persada.

Zaidan, Nur Anas, dkk.1984. Makanan Wujud,Variasi dan Fungsi Serta Cara Penyajian Daerah Sumatra Barat. Sumatra Barat: Departeman P\&K Proyek Inventaris dan Dokumentasi Kebudayaan Daerah.

Zulkarnaini. 2002. Budaya Alam Minangkabau. Bukittinggi: Usaha Ikhlas 